\title{
Anacharsis Cloots: La República universal seguido de Bases constitucionales de la República del género humano. Edición, traducción, notas y epílogo de Francisco Javier Espinosa. Pamplona: Laetoli, 2018.
}

\section{Pilar Benito Olalla \\ UNED (España)}

La paradójica Revolución francesa sigue siendo objeto de estudio y fascinación en nuestra época, y mucho más ahora, en estos tiempos de aguas revueltas en la política, de populismos a diestra y siniestra, de confusiones ideológicas e ignorancias y olvidos de la más elemental cultura democrática, así como de los entramados históricos que nos han costado nuestras libertades. Por eso, se agradece que el profesor Francisco Javier Espinosa Antón (gran especialista en Spinoza y en la Ilustración) haya traducido y editado con mimo una excelente antología de textos de uno de los personajes más emblemáticos -aunque menos conocido- de aquel proceso revolucionario, Anacharsis Cloots, defensor de una República universal y comprometido con la Revolución, pero que acabaría siendo guillotinado en 1794, engullido por el terror de Robespierre. ¿Cuáles fueron los avatares en su vida que lo llevaron al ardor revolucionario? En realidad, se llamaba Joannes Baptista Cloots, barón de Gnadenthal, nacido en 1755 en el castillo del mismo nombre (en Cléveris) y propiedad de su familia, de estirpe holandesa y católica, dedicada a las fianzas e instalada en Prusia. Eligió el nombre de Anacharsis, por ser el de un filósofo escita que conoció la república ateniense y defendió el ideal de la unificación de Grecia, Escitia y Oriente, allá por el siglo VI a.c. Ese mismo impulso republicano y universalista será el motor de todos los discursos de Cloots. Culto, cosmopolita, estuvo presente en París inmediatamente después de la toma de la Bastilla, y en la capital francesa vivió intensamente aquellos turbulentos años. El hecho concreto que marcó su entrada en la escena política fue el siguiente: el 19 de junio de 1790 accedió a la Asamblea nacional encabezando un grupo de 36 extranjeros, y sus palabras fueron: "Venimos de Europa, venimos de Asia, venimos de América. Somos la Humanidad". El discurso de Cloots causó una viva impresión y fue bautizado como "el orador del género humano". En 1792 obtuvo la nacionalidad francesa, al igual que Paine, Bentham o Washington. A continuación fue elegido diputado de la Convención y se publicó su obra más destacada, La República universal. Sus discursos enardecidos, de lenguaje 
directo y pegados a la más viva actualidad, tenían un amplio eco en sus conciudadanos. Pero las disensiones e intrigas dentro del grupo jacobino al cual pertenecía se convirtieron en una trampa mortal. Y la sombra alargada del paranoico Robespierre tendió sus redes para acusarlo de "ser barón, alemán y rico, traidor y conspirador contra la República”, como muy bien nos cuenta el profesor Espinosa Antón. Un juicio injusto condujo derecho al patíbulo a este jacobino prusiano, galófilo y ateo.

El presente libro recoge su obra más famosa ya citada, formada por una serie de discursos breves, donde se entremezclan sus ideas políticas más generales y conocidas con otras reflexiones y descripciones concretas y hasta anecdóticas, que nos acercan a las preocupaciones diarias del París revolucionario y de sus gentes. Además, está especie de crónica periodística y de marcado carácter panfletario se extiende a los avatares políticos de la Europa del momento. Por todo ello, su lectura resulta estimuladora hoy en día, más allá de algunos episodios que nos pueden resultar desfasados.

En el primer discurso, La República universal o discurso a los tiranicidas, Cloots aplaude los logros de la Constitución francesa -aun reconociendo algunas de sus debilidades-, exalta el amor a la patria, proclama el advenimiento de una nación única y critica las lacras de los nacionalismos particulares. En su afán universalista reivindica su sistema filantrópico fundado en el interés general: "Una nación, una asamblea, un príncipe" (p. 18). Su plan utópico sueña con la familia universal, donde la unidad, fruto de los derechos humanos, se armonice con la defensa de las libertades y la protección de la diversidad de cultos y culturas. Pero, al mismo tiempo, Cloots ataca las distintas formas de teísmo y argumenta con vehemencia a favor del ateísmo: "la religión es una enfermedad social que habría que curar cuanto antes. Un hombre religioso es un animal depravado" (p. 24). Y será la Ley la que reemplace a Dios. En esa nueva sociedad de libertades, de civismo, de paz perpetua, sin impuestos, se fortalecerán los valores de la fraternidad, la indulgencia. En esta apología de la República universal, no podía faltar el elogio de París, ciudad ilustrada y próspera por excelencia: "Vaticano de la razón" (p. 35), "laboratorio y crisol del espíritu humano" (p. 38). Sentencia finalmente Cloots que su sistema "claro, simple y bello" (p. 40) se acabará imponiendo por encima de todos sus enemigos.

En el segundo Discurso (que iba a ser pronunciado en el club de los jacobinos cuando la noticia del arresto del rey cambió el orden del día), Cloots hace un elogio del pueblo de París ante la deserción real que se acababa de producir y también arenga al ejército francés. Propone abolir el título de rey, dejando el poder ejecutivo en manos del primer funcionario, apelando de nuevo al civismo ilustrado.

A continuación, en el Capítulo de los sombreros proclama la prosperidad económica que vendrá con la revolución: abundancia de materias primas para los sombrereros, abundancia de comestibles gracias a la mejora de la agricultura 
y la anunciada supresión de impuestos. También destaca la importancia de la educación.

En Nuevas combinaciones del arte social trata sobre el rey Luis XVI y sus intrigas frente a la revolución en marcha. Cloots plantea serias objeciones al mantenimiento de una monarquía en un estado republicano, y -desde su postura independiente- defiende la abolición de la monarquía: “¡No más reyes, no más sacerdotes!" (p. 64). Pero no está a favor de la muerte del rey, sino de que la libertad de prensa, la educación y los valores ilustrados de la razón y la ley harán caer por su propio peso un trono inútil, absurdo y corrupto. Cloots propone a cambio una especie de "república-monarquía", donde el poder ejecutivo sea detentado por un primer funcionario retribuido de manera modesta. Toma como ejemplo a los norteamericanos que, desde su emancipación, tienen a legisladores justos que se basan en el buen sentido y el interés público.

En el Discurso contra los emigrados está en contra de la política de su momento en Francia respecto a los nobles huidos y propone buscar soluciones eficaces.

El siguiente texto, A mi tío Cornelius Pauw, es una carta a su pariente, llena de ardor patriótico, donde le cuenta las intrigas y tumultos de la corte y de algunos aristócratas en contra de la Revolución, y cómo esta se abre paso en medio de todos sus enemigos, externos e internos. Como siempre en los escritos de Cloots, está llena esta misiva de recursos retóricos y alusiones filosóficas, en este caso, de alabanza hacia Montaigne, Voltaire, Rousseau, y su propio tío, también filósofo. Y ahí resuenan las palabras de la arenga exacerbada de Cloots:

\footnotetext{
“¡Nosotros haremos tanto bien en nombre de la Constitución universal! Y en lugar de invocar a un Dios-hombre proporcionaremos los Derechos del hombre. No tendremos paz más que a ese precio. Nuestro Manifiesto contra los usurpadores contendrá una sola denuncia: el crimen de la tiranía, de lesa nación y lesa humanidad" (p. 91).
}

En el denominado Capítulo último recapitula algunas de sus ideas sobre un mundo venidero de soberanía universal, ateísmo y unidad del género humano, no sin antes pasar revista a los inminentes peligros del momento: las intrigas palaciegas, la previsible huída del rey, los enemigos de la patria, tanto aristócratas como demagogos. Ese ambiente descrito refleja a las mil maravillas el aire denso, casi irrespirable que había entonces en Francia, en que cada instante todo podía cambiar de la noche a la mañana, como si de una novela de suspense se tratara.

El libro se completa con las Bases constitucionales de la República del género humano, donde Cloots resume su sistema como la mejor apología de la Revolución y respuesta requerida por "una constitución que una la felicidad permanente y la libertad permanente" (p. 123).

El nutrido aparato de notas, la magnífica traducción y el esclarecedor y muy 
bien documentado epílogo de Espinosa Antón convierten esta edición en un libro que se lee con interés creciente, y que fomenta la curiosidad por revisitar aquella etapa y reflexionar sobre posibles concomitancias y solapamientos con la nuestra, y no olvidar nunca las crueles contradicciones de las revoluciones. Toda una invitación para valorar las libertades y la potencia de la razón frente a la barbarie y los totalitarismos de cualquier índole. 